\title{
Role of immune checkpoint inhibitors in gastrointestinal cancer treatment
}

\author{
Jakob Michael Riedl · Michael Stotz · Armin Gerger
}

Received: 30 October 2018 / Accepted: 8 January 2019 / Published online: 22 January 2019

(C) The Author(s) 2019

Summary In this short review we aim to summarize the role current clinical role of immunotherapy in particular of immune checkpoint inhibition in gastrointestinal malignancies and highlight the most important clinical trials.

Keywords Immunotherapy - Colorectal cancer · Esophageal cancer - Gastric cancer - Microsatellite instability

$\begin{array}{ll}\text { Abbreviations } \\ \text { CTLA-4 } & \text { Cytotoxic T-lymphocyte-associated protein } 4 \\ \text { GEJ } & \text { Gastroesophageal junction } \\ \text { HCC } & \text { Hepatocellular carcinoma } \\ \text { mCRC } & \text { Metastatic colorectal cancer } \\ \text { mmr } & \text { Mismatch repair } \\ \text { MSI } & \text { Microsatellite instability } \\ \text { MSI h } & \text { High microsatellite instability } \\ \text { PC } & \text { Pancreatic cancer } \\ \text { PC } & \text { Pancreatic cancer } \\ \text { PD-1 } & \text { Programmed death } \\ \text { PD-L1 } & \text { Programmed death ligand 1 } \\ \text { ORR } & \text { Objective response rate } \\ \text { OS } & \text { Overall survival } \\ \text { VEGF } & \text { Vascular endothelial growth factor }\end{array}$

J. M. Riedl, MD · M. Stotz, MD .

Associate Professor of Medicine A. Gerger, MD, MBA ( $\square)$

Division of Clinical Oncology, Department of Medicine,

Comprehensive Cancer Center Graz, Medical University of

Graz, Auenbruggerplatz 15, 8036 Graz, Austria

armin.gerger@gmx.at

J. M. Riedl, MD

jakobmriedl@gmail.com

M. Stotz, MD

michael.stotz@medunigraz.at

Associate Professor of Medicine A. Gerger, MD, MBA

Center for Biomarker Research in Medicine, Graz, Austria

\section{Introduction}

Accounting for around 4 million deaths per year worldwide, gastrointestinal malignancies are responsible for $40 \%$ of all cancer associated deaths [1]. Although major progress has been made in recent decades by optimizing cytotoxic chemotherapy and implementing targeted therapy in gastrointestinal cancer treatment there is still need for novel treatment options. The biggest breakthrough in oncology during recent years has been achieved by the Nobel Prize winning invention of cancer immunotherapy [2]. The clinical implementation of immune checkpoint inhibitors has led to remarkable progress of treatment response and disease outcome in various cancer entities such as melanoma, non-small cell lung cancer and renal cell carcinoma [3-5]. In gastrointestinal malignancies limited response rates have been observed in preliminary trials with immune checkpoint inhibitors. Still, recent trials focusing on selected subgroups of gastrointestinal cancer patients have reported promising results. Most relevant trials are listed in Table 1.

\section{Esophageal and gastric cancer}

Disease outcome and treatment response to cytotoxic chemotherapy is limited in both metastatic or locally advanced esophageal and gastric cancer. Thus, great hope lies in the implementation of immunotherapy for those highly aggressive cancer entities. The first promising results originated from the KEYNOTE-012 and KEYNOTE-028 trial, which evaluated the efficacy of the programmed death 1 (PD-1) inhibitor pembrolizumab in programmed death ligand 1 (PD-L1) positive, pretreated, advanced solid tumor patients. KEYNOTE-012 included 36 patients with advanced adenocarcinoma of the stomach or gastroesophageal 
Table 1 Selection of relevant immunotherapy trials in Gl cancers

\begin{tabular}{|c|c|c|c|c|c|c|}
\hline Trial & Phase & Entity & Setting & Biomarker & Treatment & Outcome \\
\hline \multicolumn{7}{|c|}{ Esophageal and gastric cancer } \\
\hline KEYNOTE 028 & $\mathrm{lb}$ & $\begin{array}{l}\text { Esophageal, } \\
\text { GEJ }\end{array}$ & $\begin{array}{l}\text { Advanced stage, } \\
\text { CTX resistant }\end{array}$ & PD-L1+ & Pembrolizumab & ORR $30 \%$ \\
\hline KEYNOTE 012 & $\mathrm{lb}$ & Gastric, GEJ & $\begin{array}{l}\text { Advanced, No line } \\
\text { limit }\end{array}$ & PD-L1+ & Pembrolizumab & ORR $21 \%$ \\
\hline CheckMate 032 & $1 / \|$ & $\begin{array}{l}\text { Gastric, } \\
\text { esophageal, } \\
\text { GEJ }\end{array}$ & $\begin{array}{l}\text { Advanced, CTX } \\
\text { resistant }\end{array}$ & All comer & Nivolumab vs Nivo1/lpi3 vs Ipi3/Nivo 1 & $\begin{array}{l}\text { ORR } 12 \% \\
\text { vs } 24 \% \text { vs } \\
8 \%\end{array}$ \\
\hline KEYNOTE 061 & III & Gastric, GEJ & $\begin{array}{l}\text { Advanced, 2nd } \\
\text { line }\end{array}$ & PD-L1+ & Pembrolizumab vs Paclitaxel & $\begin{array}{l}\text { OS } 9.1 \text { vs } \\
8.3 \text { (CPS } \\
>1010.4 \\
\text { vs } 8 \text { ) }\end{array}$ \\
\hline ATTRACTION 02 & III & Gastric, GEJ & $\begin{array}{l}\text { Advanced, } \geq 3 r d \\
\text { line }\end{array}$ & All comer & Nivolumab vs placebo & $\begin{array}{l}\text { OS } 5.26 \text { vs } \\
4.14\end{array}$ \\
\hline KEYNOTE 062 & III & Gastric, GEJ & $\begin{array}{l}\text { Advanced, } 1 \text { st } \\
\text { line }\end{array}$ & $\begin{array}{l}\text { PD-L1+, } \\
\text { HER- }\end{array}$ & $\begin{array}{l}\text { Pembrolizumab vs Pembrolizumab }+ \text { cisplatin }+5 \mathrm{FU} \text { vs } \\
\text { cisplatin }+5 \mathrm{FU}\end{array}$ & $\begin{array}{l}\text { Study } \\
\text { ongoing }\end{array}$ \\
\hline KEYNOTE 181 & III & $\begin{array}{l}\text { Esophageal, } \\
\text { GEJ }\end{array}$ & $\begin{array}{l}\text { Advanced, 2nd } \\
\text { line }\end{array}$ & All comer & Pembrolizumab vs investigator choice & $\begin{array}{l}\text { Study } \\
\text { ongoing }\end{array}$ \\
\hline CheckMate 648 & III & $\begin{array}{l}\text { Squamous cell } \\
\text { esophageal }\end{array}$ & $\begin{array}{l}\text { Advanced, } 1 \text { st } \\
\text { line }\end{array}$ & All comer & $\begin{array}{l}\text { Nivolumab + Ipilimumab vs Nivolumab + 5FU/Cisplatin } \\
\text { vs } 5 F U / \text { Cisplatin }\end{array}$ & $\begin{array}{l}\text { Study } \\
\text { ongoing }\end{array}$ \\
\hline CheckMate 577 & III & $\begin{array}{l}\text { Lower } \\
\text { esophageal, } \\
\text { GEJ }\end{array}$ & Adjuvant & All comer & Nivolumab vs placebo & $\begin{array}{l}\text { Study } \\
\text { ongoing }\end{array}$ \\
\hline \multicolumn{7}{|l|}{ Colorectal cancer } \\
\hline NCT01876511 & II & $\begin{array}{l}\text { Metastatic } \\
\text { carcinoma }\end{array}$ & $\begin{array}{l}\text { Advanced, CTX } \\
\text { resistant }\end{array}$ & $\begin{array}{l}\text { dMMR, } \\
\text { pMMR }\end{array}$ & Pembrolizumab & $\begin{array}{l}\text { ORR 40\% } \\
\text { (dMMR) } \\
\text { vs 0\% } \\
\text { (pMMR) }\end{array}$ \\
\hline KEYNOTE 164 & $\|$ & Colorectal & $\begin{array}{l}\text { Advanced, } \geq 2 n d \\
\text { line }\end{array}$ & MSI high & Pembrolizumab & ORR $32 \%$ \\
\hline CheckMate 142 & ॥ & Colorectal & $\begin{array}{l}\text { Advanced, } \geq 1 s t \\
\text { line }\end{array}$ & MSI high & Nivolumab + Ipilimumab & $\begin{array}{l}\text { ORR } 60 \% \\
\text { (1st line), } \\
\text { ORR } 55 \% \\
\text { ( } \geq 2 \text { nd line) }\end{array}$ \\
\hline KEYNOTE 177 & III & Colorectal & 1st line & $\begin{array}{l}\text { dMMR, MSI } \\
\text { high }\end{array}$ & Pembrolizumab & Ongoing \\
\hline COTEZO IMblaze 370 & III & Colorectal & CTX resistant & All comer & $\begin{array}{l}\text { Atezolizumab + cobimetinib vs atezolizumab vs rego- } \\
\text { rafenib }\end{array}$ & $\begin{array}{l}\text { OS } 8.9 \text { vs } \\
7.1 \text { vs } 8.5\end{array}$ \\
\hline MODUL trial & $\|$ & Colorectal & $\begin{array}{l}\text { Advanced, 1st } \\
\text { line maintainance }\end{array}$ & $\begin{array}{l}\text { BRAF wild- } \\
\text { type }\end{array}$ & FP/bevacizumab + atezolizumab vs FP/bevacizumab & $\begin{array}{l}\text { PFS } 7.1 \text { vs } \\
7.4\end{array}$ \\
\hline COMMIT & III & Colorectal & $\begin{array}{l}\text { Advanced, } 1 \text { st } \\
\text { line }\end{array}$ & dMMR & $\begin{array}{l}\text { Atezolizumab vs FOLFOX/bevacizumab + atezolizumab } \\
\text { vs FOLFOX/bevacizumab }\end{array}$ & Ongoing \\
\hline ATOMIC & III & Colorectal & Adjuvant, stage III & $\begin{array}{l}\text { dMMR, MSI } \\
\text { high }\end{array}$ & FOLFOX + atezolizumab vs FOLFOX & Ongoing \\
\hline NCT03104439 & ॥ & $\begin{array}{l}\text { Colorectal, } \\
\text { pancreatic }\end{array}$ & Advanced & All comer & Nivolumab + ipilimumab + radiation therapy & Ongoing \\
\hline \multicolumn{7}{|c|}{ Hepatocellular carcinoma } \\
\hline CheckMate 40 & $1 / 11$ & HCC & Advanced & All comer & Nivolumab & ORR $20 \%$ \\
\hline KEYNOTE 224 & $\|$ & $\mathrm{HCC}$ & $\begin{array}{l}\text { Advanced, 2nd } \\
\text { line }\end{array}$ & All comer & Pembrolizumab & ORR 17\% \\
\hline CheckMate 559 & III & HCC & $\begin{array}{l}\text { Advanced, 1st } \\
\text { line }\end{array}$ & All comer & Nivolumab & Ongoing \\
\hline Imbrave & III & $\mathrm{HCC}$ & $\begin{array}{l}\text { Advanced, 1st } \\
\text { line }\end{array}$ & All comer & Atezolizumab + bevacizumab vs sorafenib & Ongoing \\
\hline HIMALAYA & III & HCC & $\begin{array}{l}\text { Advanced, 1st } \\
\text { line }\end{array}$ & All comer & Durvalumab \pm tremelimumab vs sorafenib & Ongoing \\
\hline
\end{tabular}


Table 1 (Continued)

\begin{tabular}{|c|c|c|c|c|c|c|}
\hline Trial & Phase & Entity & Setting & Biomarker & Treatment & Outcome \\
\hline \multicolumn{7}{|c|}{ Pancreatic cancer } \\
\hline NCT00729664 & I & Pancreatic & $\begin{array}{l}\text { Advanced, } \\
\text { chemotherapy } \\
\text { resistant }\end{array}$ & All comer & Anti PD L1 antibody & ORR 0\% \\
\hline TELOVAC & III & Pancreatic & $\begin{array}{l}\text { Advanced, 1st } \\
\text { line }\end{array}$ & All comer & $\begin{array}{l}\text { Gemcitabine/capecitabine + GV1001 (sequential or } \\
\text { concurrent) vs Gemcitabine/capecitabine }\end{array}$ & $\begin{array}{l}\text { OS } 6.9,8.4 \\
\text { vs } 7.9\end{array}$ \\
\hline AM0010 & 1 & Pancreatic & $\begin{array}{l}\text { Advanced, } \geq 2 \text { nd } \\
\text { line }\end{array}$ & All comer & AM0010 + FOLFOX & $\begin{array}{l}\text { ORR } 16 \% \\
\text { DCR } 79 \%\end{array}$ \\
\hline SEQUOIA & III & Pancreatic & $\begin{array}{l}\text { Advanced, 2nd } \\
\text { line }\end{array}$ & All comer & AM0010 + FOLFOX vs FOLFOX & Ongoing \\
\hline \multicolumn{7}{|c|}{ Biliary tract cancer } \\
\hline KEYNOTE 28 & 1 & Biliary tract & Advanced & PDL1 + & Pembrolizumab & ORR $17 \%$ \\
\hline KEYNOTE 158 & $\|$ & Biliary tract & $\begin{array}{l}\text { Advanced, } \\
\text { chemotherapy } \\
\text { resistant }\end{array}$ & All comer & Pembrolizumab & ORR 5\% \\
\hline NCT03260712 & $\|$ & Biliary tract & $\begin{array}{l}\text { Advanced, 1st } \\
\text { line }\end{array}$ & All comer & Pembrolizumab + gemcitabine + cisplatin & Ongoing \\
\hline
\end{tabular}

junction (GEJ). The objective response rate (ORR) was $22 \%$ and the median overall survival (OS) 11.4 months. Grade 3 or 4 treatment related adverse events were observed in $13 \%$ [6]. In the KEYNOTE028 trial similar response rates and safety profiles could be shown for squamous cell and adenocarcinomas of the esophagus [7]. Based on the encouraging results with pembrolizumab from phase I trials several phase III trials were initiated in esophageal and gastric cancer. In the KEYNOTE-061 phase III trial pembrolizumab was compared to paclitaxel as second line treatment in a cohort of 592 patients with gastric or GEJ cancer. Pembrolizumab did not meet its primary endpoint of superior OS and progressionfree survival (PFS), however showed more durable response and a better safety profile than paclitaxel. Further, subgroup analysis suggests a greater treatment benefit for pembrolizumab in patients with an Eastern Cooperative Oncology Group (ECOG) performance status of 0 and in patient whose tumors have high levels of microsatellite instability (MSI high) or high levels of PD-L1 expression. (PD-L1 combined prognostic score $>10$ ) [8].

In addition to pembrolizumab valid data exist for the PD-1 inhibitor nivolumab. The CheckMate032 trial evaluated the treatment efficacy and safety of nivolumab alone or in combination with the cytotoxic T-lymphocyte-associated protein 4 (CTLA-4) antibody ipilimumab in chemotherapy refractory patients with esophagogastric cancer irrespective of their PD-L1 expression status. Combination immunotherapy resulted in an ORR of $24 \%$ and a 12 -month OS rate of $39 \%$ [9]. In 2017, preliminary results from the ATTRACTION-2 trial, a phase III trial which included patient with heavily pretreated advanced gastroesophageal cancer who either received nivolumab or placebo were presented. Nivolumab lead to a statistically significant prolonged median OS and higher ORR; however the survival benefit of 1.1 months was limited [10].

\section{Colorectal cancer}

In colorectal cancer only a small subgroup of patients (MSI-high) seem to benefit from immune checkpoint inhibition. Therefore, great efforts have been made to identify predictive biomarkers for treatment response. A preliminary phase II trial investigating the effect of pembrolizumab in patients with pretreated metastatic colorectal cancer (mCRC) showed high response rates in mismatch repair (MMR) deficient tumors, whereas MMR proficient cancers showed no treatment effect at all [11]. Accounting for around 5\% of all CRC MMR deficient tumors come along with a high mutational burden and neoantigen load both of which have been shown to be associated with improved response rates to anti PD-1/PD-L1 blockade [12]. Based on the encouraging findings from the NCT01876511 trial several phase II and III trials with pembrolizumab in MMR deficient mCRC patients have been started. At the 2018 ASCO meeting preliminary results from the KEYNOTE-164 trial were presented. This phase II trial evaluated the efficacy of pembrolizumab in MSI high mCRC patients who had progressed on at least one line of previous chemotherapy. An ORR of $32 \%$ and a 12 -month PFS rate of $41 \%$ indicates that pembrolizumab is also effective as second line therapy in this patient subgroup [13]. Another ongoing phase II trial investigates the efficacy of either nivolumab alone or in combination with the CTLA- 4 inhibitor ipilimumab in MMR deficient mCRC patients. Preliminary results of the second or further line cohort of 
the CheckMate-142 trial demonstrated an ORR of 31\% and a 12 -month OS rate of $73 \%$ for single nivolumab treatment and an ORR of $55 \%$ and a 12-month OS rate of $85 \%$ for combination immunotherapy [14]. As first line treatment the ORR and disease control rate (DCR) for nivolumab plus ipilimumab were $60 \%$ and $84 \%$ respectively, indicating that this combination may represent a new treatment option for MMR deficient mCRC patients. The ongoing KEYNOTE177 phase III trial is evaluating efficacy and safety of pembrolizumab versus standard of care as first line treatment in MMR deficient mCRC patients. First results are eagerly awaited and can be expected in 2019 [15].

In MMR proficient cancers which account for the vast majority of CRC immunotherapy has been mostly disappointing [11]. It is therefore of high scientific and clinical interest to find ways to make MMR proficient tumors more susceptible to immunotherapy. One approach is to combine immunotherapy with other immune modifying drugs such as vascular endothelial growth factor (VEGF) or MEK inhibitors, which have been shown to enhance T-cell infiltration and upregulation of MHC in preclinical studies [16]. However, up to the present these combinations failed to result in superior disease outcome in randomized trials. In the COTEZO IMblaze-370 trial the combination of the PD-L1 inhibitor atezolizumab with the MEK inhibitor cobimetinib did not meet its primary endpoint of prolonged OS compared to regorafenib alone in chemotherapy resistant mCRC patients.

In addition, preliminary data of the MODUL trial comparing fluoropyrimidine plus bevacizumab plus atezolizumab versus fluoropyrimidine plus bevacizumab as 1st line maintenance therapy failed to show a survival benefit for the immunotherapy combination regiment [17]. Trials combining radiation therapy with immune checkpoint inhibitors to induce an abscopal effect are ongoing.

\section{HCC}

In advanced hepatocellular carcinoma (HCC) both nivolumab and pembrolizumab have demonstrated clinical efficacy and tolerable safety profiles in patients previously treated with sorafenib the current standard of care. The CheckMate-040 trial showed an ORR of $20 \%$ for patients treated with nivolumab with a $25 \%$ rate of grade $3 / 4$ adverse events [18]. In the KEYNOTE-224 trial an ORR of $17 \%$ and a grade $3 / 4$ adverse event rate of $25 \%$ was recorded for pembrolizumab [19]. Based on these encouraging findings several phase III trials comparing immune checkpoint inhibitors with sorafenib as first line therapy are ongoing; however results are still pending.

\section{Pancreatic cancer}

Various approaches of immunotherapy including the application of checkpoint inhibitors, cancer vaccines, oncolytic viruses and adoptive $\mathrm{T}$ cell therapy have been evaluated in the treatment of advanced pancreatic cancer (PC). However, as of yet the benefit of immunotherapy in PC has been very limited. The TeloVac trial was the largest phase III trial that compared gemcitabine with the telomerase peptide vaccine GV1001 versus gemcitabine alone in advanced pancreatic cancer patients. Unfortunately, chemoimmunotherapy did not result in a statistically significant survival benefit and therefore did not meet its primary endpoint [20].

\section{Biliary tract cancer}

Preliminary results of the KEYNOTE-158 study investigating the efficacy and safety profile of pembrolizumab in advanced biliary tract cancer were presented at this year's ESMO conference. At data cut off an ORR of $5.8 \%$ could be shown indicating that immune checkpoint inhibition is effective in a small subgroup of biliary tract cancer patients [21]. Further studies are needed to verify the role of immunotherapy in this cancer entity.

\section{Conclusion}

Immunotherapy has been proved to be effective in various gastrointestinal malignancies, however careful patient selection is needed to increase treatment efficacy. In esophageal and gastric cancer patients with high PD-L1 expression and MSI high tumors seem to have the greatest benefit, which in our opinion justifies the off-label application of immune checkpoint inhibitors for this subgroup in the routine clinical setting. In 2017 the FDA approved pembrolizumab and nivolumab for MMR deficient mCRC patients after prior treatment with fluoropyrimidine, oxaliplatin, and irinotecan. Based upon results from the CheckMate-142 trial with objective response rates of up to $50 \%$ ipilimumab has gained accelerated FDA approval to be used alongside nivolumab as second line treatment in MSI high or MMR deficient mCRC. Further, in September 2017 the FDA approved nivolumab for the treatment of patients with HCC who have progressed on sorafenib. The role of first-line immune checkpoint

Table 2 Clinical practice points

Immunotherapy is effective in a subgroup of Gl cancer patients

Accurate patient selection is critical

MSI $\mathrm{H}$ and PDL 1 positive tumors seem to be most susceptible

Nivolumab and pembrolizumab FDA approved for 2nd line MSI h mCRC

Ipilimumab FDA approved alongside nivolumab in 2nd line MSI h mCRC

Nivolumab FDA approved for 2nd line HCC

Identification of further predictive biomarkers needed 
inhibition as compared with sorafenib in advanced HCC is under study for which results are expected in late 2018. In pancreatic and biliary tract cancer up to date no immunotherapy drugs have entered routine clinical practice however several promising trials are ongoing (Table 2).

Over recent years immunotherapy has constantly gained momentum in the treatment of gastrointestinal malignancies. Still, further research is needed to find ways to make immunologically cold tumors hot and to identify valid predictive biomarkers which help to match patients with the best available therapy whilst sparing others from unnecessary treatment side effects.

Funding Open access funding provided by Medical University of Graz.

\section{Compliance with ethical guidelines}

Conflict of interest J.M. Riedl, M. Stotz, and A. Gerger declare that they have no competing interests.

Ethical standards No approval by an ethics committee was needed for this review. No informed consent was applicable since this manuscript does not contain any patient data.

Open Access This article is distributed under the terms of the Creative Commons Attribution 4.0 International License (http://creativecommons.org/licenses/by/4.0/), which permits unrestricted use, distribution, and reproduction in any medium, provided you give appropriate credit to the original author(s) and the source, provide a link to the Creative Commons license, and indicate if changes were made.

\section{References}

1. Bray F, Ferlay J, Soerjomataram I, Siegel RL, Torre LA, Jemal A. Global cancer statistics 2018: GLOBOCAN estimates of incidence and mortality worldwide for 36 cancers in 185 countries. Ca Cancer J Clin. 2018;68(6) https://doi.org/10. 3322/caac.21492.

2. PardollDM.Theblockade ofimmunecheckpointsincancer immunotherapy. Nat Rev Cancer. 2012;12(4) https://doi. org/10.1038/nrc3239.

3. Motzer RJ, Escudier B, McDermott DF, George S, Hammers HJ, Srinivas S, et al. Nivolumab versus Everolimus in advanced renal-cell carcinoma. N Engl J Med. 2015;373(19):1803-13. https://doi.org/10.1056/ NEJMoa1510665.

4. Brahmer J, Reckamp KL, Baas P, Crinò L, Eberhardt WEE, Poddubskaya E, et al. Nivolumab versus Docetaxel in advanced squamous-cell non-small-cell lung cancer. N Engl J Med. 2015;373(2):123-35. https://doi.org/10.1056/ NEJMoa1504627.

5. Hodi FS, O'Day SJ, McDermott DF, Weber RW, Sosman JA, Haanen JB, et al. Improved survival with ipilimumab in patients with metastatic melanoma. $\mathrm{N}$ Engl J Med. 2010;363(8):711-23.

6. Muro K, Chung HC, Shankaran V, Geva R, Catenacci D, Gupta S, et al. Pembrolizumab for patients with PDL1-positive advanced gastric cancer (KEYNOTE-012): a multicentre, open-label, phase $1 \mathrm{~b}$ trial. Lancet On- col. 2016;17(6):717-26. https://doi.org/10.1016/S14702045(16)00175-3.

7. Doi T, Piha-Paul SA, Jalal SI, Saraf S, Lunceford J, Koshiji $\mathrm{M}$, et al. Safety and antitumor activity of the antiprogrammed death-1 antibody pembrolizumab in patients with advanced esophageal carcinoma. J Clin Oncol. 2017;36(1):61-7. https://doi.org/10.1200/JCO.2017. 74.9846 .

8. Shitara K, Özgüroğlu M, Bang Y-J, Di Bartolomeo M, Mandalà $\mathrm{M}$, Ryu M-H, et al. Pembrolizumab versus paclitaxel for previously treated, advanced gastric or gastrooesophageal junction cancer (KEYNOTE-061): a randomised, open-label, controlled, phase 3 trial. Lancet. 2018;392(10142):123-33. https://doi.org/10.1016/S01406736(18)31257-1.

9. Janjigian YY, Bendell J, Calvo E, KimJW, Ascierto PA, Sharma P, et al. CheckMate-032 study: efficacy and safety of nivolumab and nivolumab plus Ipilimumab in patients with metastatic esophagogastric cancer. J Clin Oncol. 2018;36(28):2836-44. https://doi.org/10.1200/JCO.2017. 76.6212 .

10. Kang Y-K, Boku N, Satoh T, Ryu M-H, Chao Y, Kato K, et al. Nivolumab in patients with advanced gastric or gastro-oesophageal junction cancer refractory to, or intolerant of, at least two previous chemotherapy regimens (ONO-4538-12, ATTRACTION-2): a randomised, double-blind, placebocontrolled, phase 3 trial. Lancet. 2017;390(10111):2461-71.

11. Le DT, Uram JN, Wang H, Bartlett BR, Kemberling H, Eyring $\mathrm{AD}$, et al. PD-1 blockade in tumors with mismatch-repair deficiency. NEngl J Med. 2015;372(26):2509-20.

12. Rizvi NA, Hellmann MD, Snyder A, Kvistborg P, Makarov V, Havel JJ, et al. Mutational landscape determines sensitivity to PD-1 blockade in non-small cell lung cancer. Science. 2015;348(6230):124-8.

13. Le DT, Kavan P, Kim TW, Burge ME, Van Cutsem E, Hara $\mathrm{H}$, et al. KEYNOTE-164: Pembrolizumab for patients with advanced microsatellite instability high (MSI-H) colorectal cancer. J Clin Oncol. 2018;36(15 (Suppl)) https://doi.org/ 10.1200/JCO.2018.36.15_suppl.3514.

14. Overman MJ, Lonardi S, Wong KYM, Lenz H-J, Gelsomino F, Aglietta $M$, et al. Durable clinical benefit with Nivolumab plus Ipilimumab in DNA mismatch repair-deficient/microsatellite instability-high metastatic colorectal cancer. J Clin Oncol. 2018;36(8):773-9. https:// doi.org/10.1200/JCO.2017.76.9901.

15. Diaz LA, Le DT, Yoshino T, André T, Bendell JC, Rosales $\mathrm{M}$, et al. KEYNOTE-177: Phase 3, open-label, randomized study of first-line pembrolizumab (Pembro) versus investigator-choice chemotherapy for mismatch repairdeficient (dMMR) or microsatellite instability-high (MSIH) metastatic colorectal carcinoma (mCRC). J Clin Oncol. 2018;36(4 (Suppl)) https:// doi.org/10.1200/JCO.2018.36.4 suppl.TPS877.

16. Loi S, Dushyanthen S, Beavis PA, Salgado R, Denkert C, Savas $\mathrm{P}$, et al. RAS/MAPK activation is associated with reduced tumor-infiltrating lymphocytes in triple-negative breast cancer: therapeutic cooperation between MEK and PD-1/PD-L1 immune checkpoint inhibitors. Clin Cancer Res. 2016;22(6):1499-509.

17. Grothey A, Tabernero J, Arnold D, De Gramont A, Ducreux MP, O'Dwyer PJ, et al. LBA19 Fluoropyrimidine (FP) + bevacizumab (BEV) + atezolizumab vs FP/BEV in BRAFwt metastatic colorectal cancer (mCRC): findings from Cohort 2 of MODUL - a multicentre, randomized trial of biomarker-driven maintenance treatment following firstline induction therapy. Ann Oncol. 2018;29(8 (Suppl)) https://doi.org/10.1093/annonc/mdy424.020. 


\section{short review}

18. El-Khoueiry AB, Sangro B, Yau T, Crocenzi TS, Kudo M, Hsu $\mathrm{C}$, et al. Nivolumab in patients with advanced hepatocellular carcinoma (CheckMate 040): an open-label, noncomparative, phase $1 / 2$ doseescalation and expansion trial. Lancet. 2017;389(10088):2492-502.

19. Zhu AX, Finn RS, Edeline J, Cattan S, Ogasawara S, Palmer D, et al. Pembrolizumab in patients with advanced hepatocellular carcinoma previously treated with sorafenib (KEYNOTE-224): a non-randomised, open-label phase 2 trial. Lancet Oncol. 2018;19(7):940-52.

20. Middleton G, Silcocks P, Cox T, Valle J, Wadsley J, Propper D, et al. Gemcitabine and capecitabine with or without telomerase peptide vaccine GV1001 in patients with locally advanced or metastatic pancreatic cancer (TeloVac): an open-label, randomised, phase 3 trial. Lancet Oncol. 2014;15(8):829-40.
21. Ueno M, Chung HC, Nagrial A, Marabelle A, Kelley RK, $\mathrm{Xu} \mathrm{L}$, et al. 625PDPembrolizumab for advanced biliary adenocarcinoma: Results from the multicohort, phase II KEYNOTE-158 study. Ann Oncol [Internet]. 2018; 29(suppl_8):mdy282.009-mdy282.009.https://doi.org/10. 1093/annonc/mdy282.009.

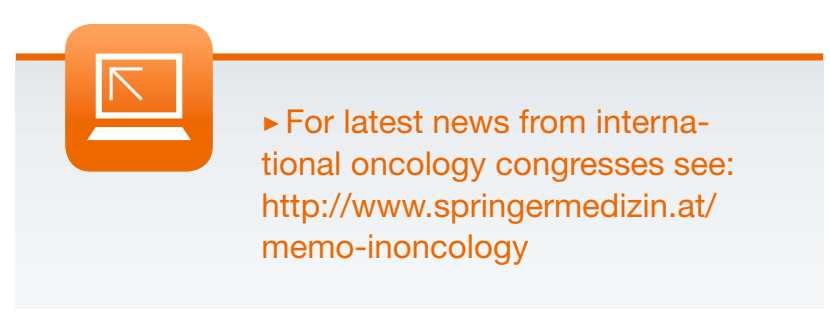

